\title{
EL VIAJE BOTANICO DE EDMOND BOISSIER AL SUR DE ESPAÑA (1837-1987)
}

\begin{abstract}
PIERRE EDMOND BOISSIER nace el 25 de Mayo de 1810 en Ginebra, en el seno de una acomodada familia de origen francés. Su pasión por los viajes le lleva desde muy joven a interesarse cada vez más por el estudio botánico de las regiones que visita. A finales de 1831 conoce en Paris a varios botánicos, entre ellos al suizo J. Gay y más tarde a B. Webb, explorador de las islas Canarias y de España. Entre 1834 y 1835 comienza a preparar el viaje a España. Aprende español y consulta toda la bibliografía necesaria. Parte por primera vez para España en 1836, debiendo regresar rápidamente por la muerte de su madre. Pero su obsesión por el Sur de nuestro país es tan grande, que no tarda en reiniciar su viaje. Este viaje, en un principio odiséico, se convierte al llegar al Sur en un goce casi permanente donde los incesantes descubrimientos se combinan con otros placeres. De regreso a Ginebra comienza a preparar su obra "Le voyage botanique dans le Midi de l'Espagne", que aparece en dos volúmenes fechados en 1839-45. El primero incluye la descripción del viaje, un capitulo importante sobre fitogeografía, así como la colección iconográfica constituida por 206 láminas de los táxones nuevos interesantes. Dichas láminas fueron realizadas por Heyland, siendo de un gran valor artístico y científico. El segundo trata exclusivamente de la flora de la región. Una dolorosa enfermedad estomacal le lleva a morir el 25 de septiembre de 1885, mientras ejercía aún con entusiasmo sus investigaciones botánicas.
\end{abstract}

\section{MOTIVOS PARA UN HOMENAJE}

Conmemorar un 150 ó 151 aniversario es en sí 10 mismo. Tan sólo la magia del cero diferencia a estas cifras.

ABM quiere rendir un doble homenaje, con estas páginas dedicadas a la expedición del botánico suizo P.E. Boissier al mediodía español. Por una parte, a la obra fruto de dicho viaje, ya que viene a ser la más importante de un momento de la botánica española carente precisamente de producción propia. Por otra parte, y más especial, a aquellos botanófilos o "botánicos secundarios" ( en el sentido más cariñoso), sobre todo andaluces, sin cuya aportación el "Voyage botanique" nunca habria adquirido tanto mérito. Si bien, en un principio, también quisimos homenajear la personalidad de Edmond Boissier, 
su prescindibilidad en este marco la encontramos más que justificada, ya que él fué figura central de múltiples homenajes. Mal se nos podría comprender si con ello se entendiese que pretendemos una labor desmitificadora. Prueba de ello son los comentarios de G. Blanca y B. Cabezudo acerca de la aportación del trabajo de Boissier al conocimiento de la flora andaluza.

Cualquier conmemoración no tiene por objeto único el mero homenaje de un singular evento; con ella el conmemorador pretende una ejemplarización. A través de las aportaciones de E. Fernández-Galiano y A. González-Bueno el lector podrá comprender que la primera mitad del siglo XIX, en la que sucede la expedición de Boissier, la ciencia botánica española, tras un floreciente periodo de grandes botánicos, se encuentra abatida por las vicisitudes sociopoliticas que vive el pais. Hoy, cuando España cuenta con un número de doctores y profesionales de la Botánica (en relación a su número de habitantes) muy superior al de la mayor parte de los paises del mundo, cabe pensar que el desarrollo futuro de nuestra ciencia está condicionado a una expansión de la misma aprendiendo del pasado cómo evitar errores.

Si hoy tuviéramos que fiscalizar a los botánicos españoles del XVIII por haber permitido que una crisis social deteriororase la ciencia que cultivaban, fundamentariamos nuestra apelación en los siguientes puntos: 1) Discapacidad critica ante el vanguardismo, motivada por un marcado obstrucionismo doctrinal, 2) Incapacidad para reconocer el valor fundamental de la ciencia que desarrollaban, acatando un reducido valor auxiliar de ciertas materias prioritarias, 3) Exceso de interiorismo, tanto en la proyección de sus trabajos, como en el ámbito de desarrollo de los mismos.

En consecuencia, mucho debemos aprender de aquel perído para que la labor de los botánicos españoles de hoy no sea infructuosa ante cualquier avatar que nos depare el futuro. En este sentido, estas páginas con las que ABM quiere rendir homenaje, constituyen un avance para el conocimiento de esta época.

\section{LA BOTANICA ESPAÑOLA EN LA PRIMERA MITAD DEL SIGLO XIX}

Ninguna ciencia, ni siquiera la Botánica sistemática, tan poco exigente en medios materiales (como lo atestiguan las penurias que sufrieron algunos botánicos del pasado siglo que realizaron, sin embargo, una notable labor científica), puede desarrollarse de espaldas al medio sociológico, politico y cultural que la rodea, y el progreso cientifico marcha, normalmente, al compás del progreso del país, la estabilidad politica y el bienestar económico.

La segunda mitad del siglo XVIII transcurrió bajo el signo de un reformismo politico impulsado por Carlos III y sus 
grandes colaboradores, Aranda, Floridablanca y Campomanes, sucesivos primeros ministros, y el afán de modificar la antigua estructura del Estado, basada en un sistema de privilegios apoyado en predominio económico y político de la nobleza y el clero. Este interesante esfuerzo culminó en importantes logros desde el punto de vista del desarrollo de la ciencia botánica en nuestro país, cuyo paradigma son la creación de una serie de instituciones donde se practicaba la investigación y la docencia en el campo de las ciencias naturales (entre otras, el Real Jardín Botánico de Madrid), y la aparición de figuras indiscutibles que impulsaron notablemente esta rama de la ciencia y establecieron relaciones con colegas europeos, equiparando a nuestro país, en estos estudios, con los más desarrollados de Europa. A esta época corresponde la realización de las grandes expediciones científicas a América; la de José Celestino Mutis a Nueva Granada (1783); la de Hipólito Ruiz y José Pavón a Perú y Chile (1777-1787); la de Martín Sessé, Vicente Cervantes y José Mociño a Nueva España (1787); a la larga expedición alrededor del mundo mandada por Alejandro Malaspina en la que figuraban los botánicos Pineda, Neé y Haenke (1789-1795); además de varias otras, con objetivos geográficos, económicos o políticos, en las que participaban también naturalistas.

Este clima politico y cientifico favoreció la promoción de un plantel de excelentes botánicos de primera fila, como fueron José Celestino Mutis (1732-1808), Casimiro Gómez Ortega (1740-1818), Antonio José Cavanilles (1745-1804), Ignacio Asso (1742-1814), Hipólito Ruiz (1754-1816), José Pavón (1754-1840), Pedro Andrés Pourret (1754-1818), Claudio Boutelou (1774-1842), Esteban Boutelou (1776-1813), Mariano Lagasca (1776-1839), Simón de Rojas Clemente (1777-1877), José Demetrio Rodríguez (1780-1846), etc. La simple lectura de estos nombres de botánicos, nacidos en el siglo XVIII y muertos en el siglo XIX, justifica el que consideremos esta época como una de las de mayor esplendor de la botánica española, por la calidad del trabajo realizado, la laboriosidad de los personajes y los resultados científicos trascendentes. Solamente el medio ambiente externo, una época de relativa estabilidad política (sobre todo si se compara con lo que habría de venir después), un renacimiento cultural impulsado desde los más altos estamentos de la nación y una apertura hacia los restantes países europeos, pudo condicionar el medio de cultivo apropiado para el florecimiento de una comunidad cientifica de tal altura, pues conviene señalar que, al lado de estos hombres singulares, proliferaba también una legión de personajes secundarios, muy merecedores de reconocimiento, cuya enumeración sería muy larga.

La muerte de Carlos III, en 1788, y su sucesión en el trono por Carlos IV, coincidió con el principio del periodo revolucionario en Francia que motivó una desestabilización política en gran parte de los paises europeos, incluida, naturalmente España, donde se manifestó en la sustitución progresiva del equipo de gobierno del anterior rey, que suscitaba desconfianza por la ideologia que representaba, por personas nuevas, entre las que ocupaba un papel predominante Manuel Godoy, primer ministro y favorito de la familia real. La caida de Godoy en marzo de 1808, fué pretexto para que una parte del pueblo de Sanlúcar de Barrameda asaltase el Jardín de Aclimatación de Plantas, institución ejemplar donde habian encontrado refugio Lagasca, Clemente y otros botánicos notables 
de la época, que no pudo ya superar la destrucción parcial de que había sido objeto y desapareció más tarde después de unos años de decadencia. Este acontecimiento puede señalarse como el principio del fin de esa época de esplendor. Cuatro años antes habia muerto Cavanilles, lo que constituyó también una gran pérdida para la Botánica española.

Simultáneamente, comenzó la Guerra de la Independencia (1808-1814), la más grande calamidad sufrida por nuestra nación en toda su historia, a la que siguió un largo período de pugnas entre liberales y absolutistas, así como guerras civiles, que determinaron una inestabilidad politica que se mantuvo más o menos hasta 1840 , cuando la derrota del carlismo decidió el triunfo liberal.

En esas condiciones, es difícil que nuestros botánicos encontrasen el sosiego y tranquilidad necesarios para realizar una buena labor, y casi todos ellos sufrieron enormes dificultades. En los años posteriores a la invasión francesa murieron Mutis (en Nueva Granada, donde se estableció con motivo de su Expedición), Gómez Ortega, Asso, Ruiz, E. Boutelou y Clemente (este último, después de muchas calamidades y penurias). Lagasca alternó su dedicación a la politica con sus aficiones botánicas, pero tuvo que pasar muchos años exiliado en Londres. Ruiz y Pavón regresaron triunfalmente de su Expedición a Perú y Chile. El primero, vivió hasta su muerte atormentado por las envidias y celos de sus colegas. Pavón sufrió mil calamidades y paseó su indignidad y su pobreza por gran parte de Europa, hasta su muerte. Pourret, debido a su nacionalidad francesa, tuvo que marchar a Portugal durante la invasión francesa, regresando después a Galicia, donde murió poco después. Casi todos los botánicos se vieron afectados por las circunstancias críticas por las que pasó España.

El antiguo esplendor de la botánica española quedó empañado y se detuvo el progreso en el pais hasta que, en la segunda mitad del siglo XIX se iniciaron los primeros movimientos intelectuales que darian lugar a un renacer de la inquietud cientifica. Muy lejos quedaban los tiempos en que Loefling escribía, sorprendido, a su maestro Linneo, que ignoraba que fueran "tantos en España los botánicos verdaderamente eruditos e insignes".

El vacío en las investigaciones botánicas fué llenado parcialmente por los trabajos de dos botánicos extranjeros, exploradores reiterados de la flora de España. Se trata de Philip Barker Webb (1793-1854), inglés, y Edmond Boissier (1810-1885), suizo, que 1legaron en un momento muy favorable para ellos por haber desaparecido los botánicos de primera clase y quedar sólo personajes de segunda fila que les ayudaron solicitamente, no recibiendo en muchos casos ninguna muestra de gratitud por parte de estos grandes maestros. Webb se mostró muy duro con la botánica española, con juicios muy severos hacia el estado de la misma (lo que motivó una réplica de Colmeirol, sin tener en cuenta las circunstancias trágicas por las que el país había pasado. Boissier fué ayudado por dos farmacéuticos malagueños, Felix Haenseler (1766-1841) y Pablo Prolongo (1806-1885), que le comunicaron con entusiasmo y no poca ingenuidad la mayor parte de sus descubrimientos que él, por supuesto, asumió con presteza.

Aparecen después dos figuras importantes que constituyen ambas un eslabón que une la generación pasada y la venidera: Miguel Colmeiro (1816-1901) y Antoni Costa i Cuixart (1817-1886). La obra del primero, voluminosa aunque poco 
consistente, ha sido poco apreciada, pero hay que reconocer que llenó un vacio en una época en que la mayor parte de la comunidad cientifica se encontraba desarticulada, inactiva y dispersa; quizá por ello alcanzó puestos importantes que le valieron la envidia y la crítica de muchos de sus contemporáneos. Costa, catedrático de la Universidad de Barcelona, fué el restaurador de la botánica catalana y creador de una escuela cuyos trabajos se prolongaron hasta entrado el siglo XX.

Y después se entró ya en la segunda mitad del siglo XIX, época en que el panorama cambió radicalmente. Al tiempo que España recibía una legión de exploradores botánicos extranjeros, entre ellos Mauricio Willkomm (1821-1895), que prestó una colaboración ejemplar a sus colegas españoles, floreció una generación de botánicos que iban a conseguir que se entrase en el sigle XX con un panorama esperanzador para la Botánica española.

E. Fernández Galiano

Departamento de Biología Vegetal

Facultad de Biología

Universidad Complutense. Madrid

\author{
ALGUNAS NOTAS RETROSPECTIVAS SOBRE EL ESTADO \\ DE LA BOTANICA EN ANDALUCIA.
}

A finales de la primavera de 1837, Pierre Edmond Boissier (1810-18.85), un joven viajero ginebrino (1) desembarca en Málaga; su interés por Andalucía sobrepasa la mera curiosidad romántica, su atracción hacia estas tierras del sủr no está vinćulada al "descubrimiento" de sus costumbres y tipos populares tan atrayentes para sus coetáneos europeos (2); e1 folklore, aún presente en su narración y por ende en la intencionalidad de su visita (3) es un elemento más del paisaje, integrado en la descripción conjunta del medio. E. Boissier viene a Andalucía dispuesto a estudiar la vegetación del viejo Reino de Granada, un territorio de alto interés geobotánico (4) sobre el que debió interesarse a raíz de su estancia en París, en el invierno de 1831-32, tras establecer contactos con Jacques Etienne Gay (1786-1864) y Philipp Baker Webb (1793-1854) (5).

Los datos disponibles sobre la flora andaluza eran en verdad escasos; E. Boissier sólo pudo disponer (6) de los catálogos anexos al "Ensayo sobre las variedades de la vid común" de S.R. Clemente (7), las descripciones de M. Lagasca y J.D. Rodríguez elaboradas sobre material herborizado por G. Thalacker (8) y la escasamente aprovechable flórula publicada por J.B.G.M. Bory de St. Vicent (9), resultado de la expedición militar francesa de 1802. Aunque aún inéditas, también tuvo acceso a las colecciones de P.B. Webb, recolectadas en 1827 (10) y a lias menos interesantes, pero también útiles, de J.P. Rambur (11). Bien poco para un territorio tan rico, pero no tan mal conocido como pudiera pensarse; un grupo de botanófilos habia herborizado, con más o menos intensidad los territorios entonces visitados por E. Boissier; algunos de ellos pudieron 
relacionarse con él, a otros sólo les conoció a través de sus herborizaciones, los más pasaron desapercibidos. Conviene ahora intentar una aproximación al estado de la botánica en Andalucia durante el primer viaje del ginebrino a España.

\section{DE MALAGA A CADIZ: UNA RED DE CORRESPONSALIAS BOTANICAS.}

"La botanique est restée bien en arrivève en Espagne, et cette décadence coincide justement dans les autres contrées de 1'Europe son plus grand essor" (12) para seguir más adelante "Madrid est le seul point de la peninsule où il soit possible de faire des études passables de botanique. Il se donne (...) quelques cours de cette science à Barcelona, à Valence, à Cadix; mais ils sont (..) destinés (..) a donner quelques idées superfielles aux jeunes médicins, et nónt amené jusqu'ici aucun résultat practique quant à la connaissance de la flore espagnole" (13). Apreciaciones justificadas y, en todo, coincidentes con las que Antonio Cabrera proporcionara años antes (14) a Carl Adolf Agardh en su "De estudio Botanica apud Hispanos" (15).

La muerte de A.J. Cavanilles, cuando su naciente escuela estaba aún inmadura, al menos para mantener las riendas de la investigación botánica en este país (16); el cambio en la línea prioritaria de investigación, donde los estudios taxonómicos pasan a estar al servicio de la demanda agrícola (17) y, desde luego, las incursiones francesas en el territorio peninsular (18), son causas suficientes para explicar el retraso, motivado por el desinterés político, hacia estos temas; aparecen lejanos las reformas borbónicas ilustradas donde la botánica, bajo la protección de Carlos III, fué la ciencia promovida, desde la corona, para modernizar la sanidad española. (19).

Algo quedó de aquellos días, no tan lejanos en el tiempo como pudiera hacer pensar el escaso desarrollo de esta ciencia; la idea de "Socios Correspondientes o Comisionados" formulada en el Reglamento del Jardín Botánico aprobado en 1783 (20) está latente en este grupo de botanófilos, y la sombra del centro madrileño se proyecta sobre ellos, unificando y apoyando sus esfuerzos herborizadores. Es ésta la primera, y prácticamente única, característica común del conjunto de estudiosos de quienes nos vamos a ocupar; su vinculación, en mayor o menor grado, a la institución central; a su director, M. Lagasca en el momento de esta primera visita de E. Boissier a España (21), envian testimonios de herbario y consultan dudas acerca de sus determinaciones o necesidades bibliográficas. Esta comunicación establecida entre Madrid y distintos puntos de la geografía andaluza, se ve completada por otra, no menos intensa, entre los propios corresponsales andaluces del Real Jardin. Sobre la correspondencia cursada entre ellos y la enviada a M. Lagasca basaremos las lineas que siguen ( 22 ).

Comencemos por Málaga, pués aquí tuvo lugar el primer encuentro de E. Boissier con los botánicos andaluces; apenas desembarcar, no sin problemas en la aduana (23), travó contacto con Félix Haenseler (18..-1841), un bávaro nacionalizado español (24) llegado a nuestro país al servicio del ejército capitaneado por el suizo Teodoro Reding (25) y afincado definitivamente en suelo andaluz; boticario de profesión, se aficionó a los estudios botánicos durante la estancia de S.R. Clemente y F.A. Zea en Málaga, comisionados para cargos de responsabilidad política (26); su relación con el Real Jardín se establece a comienzos de 1814 , a raíz de una carta de 
presentación enviada a M. Lagasca por A. Cabrera ( 27 ); 1a prometedora actividad botánica sospechada por el magistral de Cádiz va a verse truncada por una nueva afición, la ictiologia, a la cual dedicará sus esfuerzos desde mediados de 1815 , según se desprende de la correspondencia mantenida entre $F$. Haenseler y J.J. Muñoz Capilla, agustino cordobés, también con aficiones botánicas; a este interés por los peces, confirmado y compartido por A. Cabrera (29), hemos de añadir una cierta incapacidad laboral, al menos desde finales de 1821 (30), motivada por el mucho aprecio al vino que hizo Haenseler, causa de su ruina física y también económica; es un hecho constatable su penuria monetaria, en 1824 se vió obligado a vender parte de su biblioteca al también farmacéutico malagueño Vicente Navarro (31). Asi pués, E. Boissier no se encuentra con un F. Haenseler repleto de fuerzas, sino con una persona abatida, falta de energía, que habría de morir apenas tres años después.

En plena juventud, contaba 31 años a la 11 egada del ginebrino, halló a quien habría de conservar el legado Haenseler; también farmacéutico, Pablo Prolongo (1806-1885) había estudiado en Madrid con S.R. Clemente y J.D. Rodríguez, con seguridad durante dos años (1830-32) y probablemente durante los cinco anteriores, mientras cursaba farmacia en el Real Colegio de San Fernando (1825-1830); aunque ejerció su profesión desde una oficina abierta al público (32), nunca abandonó su deseo de ingresar en los cuerpos docentes, aunque sin éxito; de hecho, su vuelta a Málaga en 1832 , ocurre tras una frustrada oposición destinada a proveer una plaza de viceprofesor de Botánica en el Museo de Historia Natural (33).

La mayor fuente de información disponible en Málaga para los trabajos de E. Boissier fué, sin duda, el herbario Haenseler (34), no sólo por las recolecciones de éste, sino por los muchos pliegos intercambiados y testificados por otros botánicos de prestigio, a más de los nacionales (Lagasca, Cabrera, Clemente) otros europeos (Agardh, Schousboe, De Candolle, entre ellos).

En Córdoba, los estudios botánicos estaban liderados por José Jesús Muñoz Capilla (1771-1840) un religioso agustino más conocido por sus escritos sobre gramática y teología que por sus estudios sobre vegetales ( 35 ); aunque ya de edad avanzada a la 1 legada de E. Boissier a Andalucía, había realizado una importante labor recolectora, parte de la cual pudo ser estudiada en el herbario Haenseler. La correspondencia cursada entre el agustino y M. Lagasca fué intensa, conocemos la mantenida entre 1814 y 1837 , de su lectura se deduce no sólo un fuerte vinculo de amistad personal (36), sino también el papel coordinador jugado por el agustino en el envio de material cordobés y jienense al Jardin de Madrid. Los pliegos herborizados en Jaén procedían, en su mayor parte, de las excursiones realizadas por Bernabé José Vassallo (37), son frecuentes los envios de cereales, coincidentes con la estancia en Londres de M. Lagasca, pero su interés por los vegetales sóbrepasa los meramente cultivables.

No disponemos de constancia escrita justificativa de las relaciones entre el agustino y A. Cabrera (38), pero los datos indirectos conocidos prueban su evidencia; J.J. Muñoz Capilla intervino en las Cortes de Cádiz como miembro de la Junta Eclesiástica de Sevilla; herborizó en Cádiz y Chiclana, lugares clásicos del magistral y en su herbario son muy frecuentes las donaciones de éste (39).

Con intención de completar esta visión general, mencio- 
naremos a José de León y Mesa (1788-1863); sus biógrafos (40) l.e mantienen alejado de Córdoba desde 1808 , nuestros datos permiten asegurar su estancia en esta ciudad, al menos de manera ocasional en 1814, herborizando en compañia de J.J. Muñoz Capilla; el dato, aunque de escasa relevancia para el desarrollo de los estudios botánicos andaluces, tiene su interés en la historia de la botánica española; su vinculación con M. Lagasca, su talante liberal y el hecho de su elección como diputado en las Cortes de 1837, todo ello dentro de un contexto próximo al Real Jardín, dentro del cual no habia sido integrado hasta ahora más que como discente (41), son datos a valorar dentro de la historia social y política del momento.

Más interés para el tema abordado tiene el tío de éste, Rafael de León Gálvez (1772-1811), muerto prematuramente, pero a quien le cabe la responsabilidad de iniciar este grupo de botanófilos cordobeses, reunido en torno a la botica de Roque Muñoz Capilla (42), su herbario no carente de valor botánico, le relaciona con Bruno Fernández, probablemente su maestro, para nosotros desconocidö.

Granada no había recibido aún a Mariano Amo y Mora (1809-1894), quien ya había obtenido su titulo de licenciado (43), pero allí residía Pedro Campo Pérez (1800-1880), con farmacia abierta desde 1825, y valioso rodrigón del futuro catedrático de materia farmacéutica animal y mineral (54); su aportación a la botánica, tanto o más valiosa que la de quien pasa por su maestro (44) está aún mal estudiada (45); desde luego trabó conocimiento personal con E. Boissier (46).

Y terminamos en Cádiz (47), la breve estancia del ginebrino en el extremo occidental de Andalucía le impidió conocer en profundidad la riqueza botánica del territorio y también a los buenos aficionados a esta ciencia; ciertamente el más destacado de sus cultivadores no foráneos (48), Antonio Nicolás Cabrera y Corro (1762-1827) habia fallecido ya (49), pero su herbario (donde se compilaba material de S.R. Clemente, P. Lallave, el interesado grupo de aficionadas gaditanas, con Josefa Lapiedra y Frasquita Larrea (50) a la cabeza, los resultados de los estudios realizados en los jardines de aclimatación de Sanlúcar de Barrameda (con material de F. Therán, J.A. Martinez Eguilar, F.P. Rodriguez y otros) (51) y Cádiz, con algunas plantas americanas y asiáticas de interés (52), los intercambios con M. Lagasca, P.K.A. Schousboe, C.A. Agardh y, por supuesto, con los ya citados andaluces) estaba aún disponible para su estudio, era propiedad de sus discípulos más destacados: Lucas Tornos Usaque (1803-1882) y Juan Bautista Chape Guisado (1800-1887); lástima que este gran herbario, máximo exponente de la tradición botánica andaluza durante el eslabón de los siglos XVIII y XIX haya desaparecido sin haber visto los tórculos los muy interesantes datos conservados en él.

\section{NOTAS}

1. Pese a su condición de ciudadano francés, como ha argumentado H.N. Burdet, "Boissier, Leresche, Levier et l'Espagne; notes biographiques et bibliographique". Mém. Soc. Bot. Genéve 1:139-154. Genéve, 1979 .

2. Sobre este interés romántico por la cultura andaluza ha insistido M. Bernal Rodríguez. "El "descubrimiento" europeo de Andalucia." En: A. Miguel Bernal (dir.). Historia de Andalucía 6:152-213. Barcelona, 1984. Consultar también, para el caso que nos ocupa, las aportaciones 
de J. Descola. La vie quotidienne en Espagne au temps de Carmen. Paris, 1971 y L.F. Hoffman. Romantique Espagne. L'image de l'Espagne en France entre 1800 et 1850. New Jersey, 1961.

3. Así sus impresiones sobre bandolerismo, corridas de toros, indumentaria femenina, contrabandistas, estudiantinas, alojamientos y un largo etcétera que pasa por la descripción de su propio traje de viaje. Cf. E Boissier, Voyage botanique dans le midi de l'Espagne pendant l'année 1837. paris, 1839-1845. 2 vol. Para el aspecto comentado es, en especial, interesante "première partie. Narration et géographie botanique". (pp. 3-180).

4. "Une de plus arrières (...) et en même temps des plus intéressantes était le royaume de Grenade $(\ldots)$ présenter les faits le plus intéressants de géographie botanique". E. Boissier, op.cit. nota 3 , pp. 4-5.

5. Cf. H.M. Burdet, op.cit. nota 1, p 140.

6. Cf. E. Boissier, op.cit. nota 3,p. 6 .

7. S.R. Clemente Rubio, Ensayo sobre las variedades de la vid común que vegetan en Andalucía, con un indice etimológico y tres listas de plantas, en que se caracterizan varias especies nuẹvas. Madrid, 1807; en la edición de Villalpando, la segunda, del mismo año, por el Semanario de Agricultura, carece de las listas de plantas. Una traducción al francés, Paris, 1814; otra al alemán, Graz, 1821; una tercera edición al castellano, Madrid, 1879. Sobre las diferencias entre estas ediciones cf. M. Colmeiro, La botánica y los botánicos de la Península Hispano-Lusitana. Madrid, 1858, p. 86 y M. Comerge Gerpe, "La creación de una escuela botánica de variedades españolas de Vid". Anales R. Acad. Farm. 2:131-140. Madrid, 1944.

8. M. Lagasca y J.D. Ródríguez, "Descripción de algunas plantas que colectó D.G. Thalacker en Sierra Nevada". Anales Ciencias Naturales 5:263-288. Madrid, 1802.

9. J.B.G.M. Bory de Saint-Vincent, "Flórula de Sierra Nevada". Annal. Gén. Sci. Phys., Bruselas, 1820 (no visto, citado según M. Colmeiro, Enumeración y revisión de las plantas de la península hispano-lusitana e islas Baleares. Madrid, 1885, t. 1, p. CCXVV).

10. "Iter hispaniense...", donde se incluyen los primeros resultados de los estudios de P.B. Webb sobre sus herborizaciones españolas apareció más de seis semanas después que "Elenchus"..." texto de E. Boissier donde se reseña ya el viaje de éste por Andalucía: así lo hace constar el ginebrino en carta a G. Bentham (cf. F.A. Stafleu, "Taxonomic Literature", Regnum Vegetabile 52:494. Utrech, 1967).

11. Colección conservada hoy en herbario P (cf. I. Heltis Veyter, "Collectors N-R", En: F.A. Stafleu (ed.), "Index Herbariorum" part 2(5), Regnum Vegetabile 109:731. Utrech, 1983.

12. E. Boissier, op.cit. nota $3, p .3$.

13. E. Boissier, op.cit. nota $3, p .4$.

14. En carta fechada en 20 de junio de 1815.

15. Incluido en los manuscritos de A. Cabrera conservados en la Universidad de Lund (Smal. Agardh, C.A.11). De ellos preparamos una edición crítica.

16. Prueba de ello son las intrigas iniciadas tras su muerte para obtener la dirección del Real Jardín; la tendencia jardinero-agrícola representada por Claudio Boutelou (1774-1842) resultó triunfante ante la escuela de A.J. Cavanilles, personificada en la figura de M. Lagasca; Francisco Antonio Zea (1766-1822), director teórico de la institución, pactó para ello con los defensores de la botánica aplicada. La correspondencia mantenida entre S.R. Clemente y J. Pozo con M. Lagasca durante 1804-1806 es muy ilustrativa a este respecto (cf. Archivo Real Jardín Botánico de Madrid -Arch. R.J.B.- leg. I,56,4,20 y leg. I,57,1,25). 
17. La edición en el Real Jardín del "Semanario de Agricultura y Artes dirigido a los Párrocos (cf. F. Díez Rodríguez, Prensa agraria en la España de la Ilustración, Madrid, 1980) y el proyecto de implantación de nuevos jardines botánicos (cf. Oficio de P.Ceballos a F.A. Zea, San Lorenzo, 18-XII-1805. Arch. R.J.B. leg. I,23,2,16; también Semanario de Agricultura y Artes 489:305-310. Madrid, 15-V-1806) son algunos hechos que hacen visualizar este cambio.

18. No sólo la entrada de Murat en Madrid (23-III-1808) también la intervención armada de los "Cien mil hijos de San Luis" al mando del Duque de Angulema (7-IV / 10-X-1823).

19. "Ciencia del estado" por excelencia; la más beneficiada dentro del proyecto ilustrado diseñado por el marqués de la Ensenada (cf. A. Romeu de Armas, Origen y fundación del Museo del Prado. Madrid, 1980); la que más dinero hizo gastar a la Corona (cf. J.C. Arias Divito. Las expediciones cientificas españolas durante el siglo XVIII. Madrid, 1968) y la que mayor número de establecimientos y personal científico movilizó en Iberoamérica (cf. A. Humbolt, Ensayo político sobre el reino de Nueva España. México, 1941). Desde luego el interés de los productos vegetales americanos sobrepasa, con mucho, los limites puramente cientificos.

20. La figura de "correspondiente" se regula en el artículo 26 del reglamento citado (Arch. R.J.B. leg. I, 3,45).

21. Mariano Lagasca (1776-1839) fué nombrado director del Real Jardín en dos ocasiones: tras la retirada francesa en 1814 hasta la entrada de las tropas del Duque de Angulema (20-III-1823) y, en 1835, tras su vuelta del exilio en Gran Bretaña, entonces ocupó la presidencia de la Junta de profesores encargados de la dirección del Museo de Ciencias Naturales, y por ende la aneja del Real Jardín. Cf. además de sus biógrafos (E. Carreño, "Notice sur la vie et les écrits du botaniste espagnol D. Mariano Lagasca". Annales Science Naturales (Botanique) 14:146-161. París, 1840, y A. Yáñez, Elogio histórico de D. Mariano Lagasca. Barcelona, 1842) la biografía manuscrita conservada en el archivo del Museo de Ciencias Naturales ("Papeles de la familia Graells", sin catalogar). S. Castroviejo, "El Real Jardín Botánico como establecimiento científico" En: S. Castroviejo $\varepsilon$ al., Real Jardín Botánico de Madrid. Pabellón de invernáculos. Noticias de una restitución histórica, pp. 42052. Madrid, 1983, ofrece una relación de biografías más recientes sobre M. Lagasca.

22. La correspondencia recibida por M. Lagasca se conserva en Arch. R.J.B. en legajos incluidos en las carpetas I,56 y I,57; su catalogación y ordenación se debe a Francisco Pelayo, Pilar Coello y Mónica Luengo; a ellos y a Alicia Ferrándiz y José Luis Diaz, también ocupados en la catalogación de este archivo, mi agradecimiento por su colaboración desinteresada e inestimable. Las relaciones entre M. Lagasca y J.J. Muñoz Capilla son analizadas a través de la correspondencia conservada en el Colegio de los Agustinos Filipinos de Valladolid; ésta fue publicada en la Revista Agustiniana (42046. Valladolid, 1884) y reimpresas por M. Laza Palacios, "Estudios sobre la flora andaluza". Anal. R. Acad. Farm. 11:157-199, 3670411, 497-556. Madrid, 1945. La correspondencia publicada entre el agustino y M. Lagasca se completa con la aún inédita conservada en Arch. R.J.B., leg. I,56,6,23 a leg. $I, 56,6,30$.

23. Cf.'E. Boissier, op.cit. nota $3, p \cdot 55-56$.

24. Naturalizado español por ley de 8-XI-1820 (cf. M. Laza Palacios, op.cit. nota 2, p. 160 y R. Roldán Guerrero, Diccionario biográfico y bibliográfico de autores farmacéuticos españoles, 2:569-571. Madrid, 1975).

25. Su pertenencia a este ejercito hizo pensar a alguno de sus coetáneos que tal era su nacionalidad, cf. carta de A. Cabrera a M. Lagasca, Cádiz, 4-XII-1813: "En Málaga en la Botica, qe. llaman de la Espartería (...) se halla de Oficial un Zuizo, qe. habiendo venido a servir en el exercito le dexó al principio de esta rebuxina (...) Se llama D. Felix Haenzeler". (Arch. R.J.B. leg. I,56,3,25).

26. Asi lo relata el Magistral en carta enviada a M. Lagasca: "Quando estubieron en aquella Ciud. Zea de Prefecto, y Clemente so sosio, ó secretario suyo trabaron con el amistad (...) Ellos me le hicieron conocer, ó por decir mejor fueron ocacion de qe. le conociese". (cf. 
nota 25). Sobre la biografía de Francisco Antonio Zea (1766-1822) y su actividad politica, que sobrepasa con mucho, a la botánica, cf. el capítulo correspondiente, elaborado por T.F. Glick, en J.M. López Piñero \& al., Diccionario Histórico de la Ciencia Moderna en España, 2:452-453. Barcelona, 1983, y la literatura secundaria en él citada.

27. "Me ha rogado por cartas, qe. le introdusca en el fabor de V. y en su correspondencia. Y pareciendome, qe. de un Joben, como es el, aplicado, y curioso, puede sacarse bastante partido, aunqe. no sea mas, qe. para recoger, y remitir las Plantas de aquellas tierras, fecundisimas, y abundantissimas de begetales (...) me atrebo á recomendarselo á $V$, y luego qe. me haya contextado qe. no halla inconveniente le escriviere á el, segun es de activo diligente è instruido" (cf. nota 25 ).

28. F. Haenseler escribe a J.J. Muñoz Capilla: "Trabajo ahora con especialidad en la ichtiologia malacitana, para 10 he formado ya tambien una especie de tratado elemental..." (Málaga, 4-III-1817). Cf. M. Laza Palacios, op.cit. nota 22, p. 183. De temática similar es el resto de la correspondencia cursada entre F. Haenseler y J.J. Muñoz Capilla (cg. p.ej. la firmada en Málaga a 25-VI-1817; op.cit. nota 22, pp. 186-187).

29. Juntos debieron publicar un folleto titulado "Lista de los peces del mar de Andalucía"; al menos asi se desprende del comentario de M. Laza Palacios (op. cit. nota 22, p. 161) y de la citación de M. Menéndez Pelayo en La Ciencia Española, 3:276. Madrid, 1876, quien precisa 1817 como fecha de publicación. Nosotros no conocemos este escrito; tan sólo una reimpresión en Rev. Progr. Ci. Exact. Fis. Nat. 22(3):141-189. Madrid, 1887-1889, debida a M.P. Graells, quien parte de un impreso incompleto (cf.p. 189). En carta de A. Cabrera a S.R. Clemente (Arch. R.J.B. leg. I,57,9,19), firmada en Cádiz a 16 de diciembre de 1821, y donde se trata, por extenso, del tema de los peces andaluces, no hay alusión a este folleto impreso.

30. "Haenseler ha dado en vino ya se ve como Suizo, y viviendo en Málaga, se ha arruinado, se ha abandonado, y asi le tengo por inutil". (A. Cabrera a S.R. Clemente, Cádiz, 16-XII-1821. Arch. R.J.B. leg. I, 57,8,19).

31. Asi consta en el primer volumen de la que fuera su "flora Española..." de J. Quer, comprada el 24 de octubre de 1824 "en 200 reales toda la obra, que son seis tomos" (cf. M. Laza Palacios, op.cit. Nota 22, p.161).

32. Pese a las muchas biografías disponibles sobre este farmacéutico (M. Colmeiro, op.cit. nota 7; E. Maffei y R. Rua Figueroa, Apuntes para una biblioteca española. Madrid, 1871-72; B. Antón Ramírez. Diccionario de bibliografía agronómica y de todas clases de escritos relacionados con la agricultura. Madrid, 1865; M. Ovilio Otero, Manual de biografía y bibliografia de los escritores españoles del siglo XIX. Paris, 1859; M. Laza Palacios, op.cit. nota 22) ninguna tan completa como la publicada por M. Casado, Elogio fúnebre del señor don Pablo Prolongo. Málaga, 1886, donde puede encontrarse un listado de sus obras inéditas (cf. también R. Roldán Guerrero, op.cit. nota 29, 4:168-171. Madrid, 1976). Su labor fundamental está ligada a la Sociedad Malagueña de Ciencias, para comprender este contexto social es de utilidad el trabajo de J.L. Carrillo \& al., La Sociedad Malagueña de ciencias. Catálogo de sus manuscritos. Málaga, 1984; el contenido del libro supera al de la mera catalogación insinuado en su título (cf. pp. 1-64).

33. Datos sobre esa oposición en M. Colmeiro, "Bosquejo histórico y estadistico del Jardín Botánico de Madrid". Anal. Soc. Esp. Hist. Nat. 4:211-345. Madrid, 1875 (cf. p. 291).

34. Catalogado por M. Laza Palacios, op.cit. nota 22. Se conservan 545 pliegos.

35. Cf. M. Menéndez Pelayo, Historia de los hetèrodoxos Españoles, Madrid, 1881. En especial los capítulos II ("La heterodoxia en las Cortes de Cádiz") y III ("La hetorodoxia durante el reinado de Fernando VII") del tomo III. Datos biográficos en la nota de las páginas 531-532 del citado tomo; M. Menéndez Pelayo se admira "que el P. Muñoz permaneciera tan fervoroso católico y ejemplar religioso, encasillándose al mismo tiempo en el sensualismo cerrado, ..." (cf.p.532), sin duda en algo debió influir su atracción por el estudio de los vegetales. 
36. Expresiones del tipo "Antonia e hijos (...) se acuerdan mucho de usted y de toda la familia" no son raras en el epistolario, sobre todo en el correspondiente a la etapa en Londres y posterior (el parráfo entrecomillado en carta de M. Lagasca a J.J. Muñoz Capilla, Madrid, 28-XII-1835, cf. M. Laza Palacios, op.cit. nota 22, p.553) ¿Tuvo J.J. Muñoz Capilla relación con el viaje de la familia Lagasca a Cádiz y posteriormente a Londres?. No debe olvidarse la excepcional acogida dispensada por el magistral ("la familia de Lagasca esto es su mujer y cuatro hijos después de haberlos tenido yo á mi cargo dos años se embarcó, y antier sarpó de este puerto para Londres...". Correspondencia de. A. Cabrera con S.R. Clemente, Cádiz, 16-XII-1825. Arch. R.J.B. leg. I,57,8), la influencia del agustino dentro de su orden (fue prior en su convento de Nuestra Señora de la Regla en Córdoba), ni la antigüedad del asentamiento de la comunidad agustiniana en Cádiz. ¿Hasta qué punto los corresponsales del Real Jardín no actuaron, en la medida de su posibilidades, como cadena de socorro para los necesitados liberales y sus familias tras la llegada de las tropas al mando del Duque de Angulema? Este no es un caso aislado.

37. No conocemos más datos sobre este botanófilo; su nombre no aparece en las recopilaciones de C. Fernández López, "Botánicos y exploraciones botánicas en la provincia de Jaén". Anuario del Adelantamiento, 25:85-96. Cazorla, 1984; "Estado del conocimiento de la flora en la provincia de Jaén". Blancoana 3:99-103. Jaén, 1985. Al menos parte de las herborizociones atribuidas a J.J. Muñoz Capilla en estos estudios corresponden a J. Vasallo, a tenor de la bibliografía disponible (cf. M. Laza Palacios, op.cit. nota 22). Conocemos su correspondencia con M. Lagasca, conservada en Arch. R.J.B. leg. I,57,42,22 a I,57,4,27, cursada entre el 20-VIII-1815 a 29-VI-1820.

38. Salvo un comentario aislado entre su correspondencia con M. Lagasca; "este jardín está muy pobre respecto de lo que fue en 1804; mas espero que usted nuestro amigo D. Antonio Cabrera y otros que aman la Botánica me auxiliaran ..." (Correspondencia entre M. Lagasca " J.J. Muñoz Capilla, Madrid, 30-VIII-1814, cf. M. Laza Palacios, op.cit. nota 22, p.167).

39. Una relación de los pliegos contenidos en este herbario en D. Jordano y M. Ocaña, "Catálogo del herbario de los botánicos cordobeses Rafael de León y Gálvez, Fr. José de Jesús Muñoz Capilla, Rafael Entrenas y Antonio Cabrera". Anal. Inst. Bot. A.J.Cavanilles 14:597-715. Madrid, 1956 .

40. Cf. la reciente tesis doctoral de 0. Adánez Suárez. La Materia Farmacéutica de León y Mesa. Facultad de Farmacia, Universidad de Alcalá de Henares, 1986, y la literatura secundaria en ella citada.

41. "Estudió además, dos cursos de Botánica, con el inolvidable D. Casimiro Gómez Ortega, y con el abate Cabanillas (sic.)" R. Roldán Guerrero, op.cit. nota 29, 3:42. Madrid, 1975. Sus vinculaciones con la botánica y los botánicos españoles van más allá de lo sospechado hasta ahora (cf. las estrechas relaciones con M. Lagasca y el grupo de botanófilos cordobeses en $M$. Laza Palacios, op.cti. nota 22).

42. Asi lo reconoce J.J. Muñoz Capilla en la biografía colocada en la portada de su herbario: "estudió farmacia en la botica de Roque Muñoz Capilla, bajo la dirección de Bruno Fernández; cultivó un Jardín Botánico en la botica" (cf. D. Jordano y M. Ocaña, op.cit. nota 39, p. 602.

43. Mariano Amo y Mora (1809-1894), se licenció en Madrid, en el Colegio de San Fernando, el año 1834; fue nombrado catedrático de la Facultad de Farmacia de Granada, en 30 de agosto de 1850, recién creada ésta (cf. C. Rodríguez López Neyra y J.M. Clavero Armenteros, Primer siglo de la Facultad de Farmacia de Granada. Resumen Histórico. Granada, 1950).

44. No coincidimos con la opinión de V. Sebastián Iranzo, Mariano de 'Amo y Mora, farmacéutico y botánico español". Libro de Actas. Congreso Internacional de Historia de la Farmacia, p.p.383-386. Granada, 1985 (1986); antes bien, pensamos que su figura ha sido sobrevalorada y está necesitada de un estudio crítico, no apologético, para situarla en su justo lugar. 
45. El herbario de M. Amo, con pliegos herborizados por P. Campo Pérez, se conserva hoy en la Facultad de Farmacia de Granada (cf. J.M. Muñoz Medina, Discurso de apertura, curso 1962-63. Granada, 1962) aunque en realidad fue donado al Instituto de Granada (hoy Instituto Padre Suárez), para engrandecer la colección formada por el entonces catedrático de Historia Natural, Rafael Garcia Alvarez; en el citado instituto se conserva un catálogo manuscrito de los pliegos pertenecientes a este herbario (cf. L. Castellón Serrano \& al., "El Museo de Ciencias Naturales del Instituto Padre Suárez de Granada". I Simposio sobre problemáticas de los Museos de la Ciencia: 7. Granada, s.f. 1983).

46. Cf. H.M. Burdet, op.cit. nota 1,p. 140.

47. Parece necesario justificar Sevilla, la ausencia más llamativa en este rápido recorrido; tras la muerte de Pedro Abad, en 1800, los estudios botánicos en esta ciudad dejan de practicarse (cf.A. Hermosilla Molina, Cien años de Medicina Sevillana, la Regia Sociedad de Medicina y demás Ciencias, de Sevilla, en el siglo XVII, Sevilla, 1970. -en especial pp. 165-178-). Su discípulo más directo, José Demetrio Rodríguez (1780-1846) se trasladó a Madrid, estudió en el Real Jardín y, junto con M. Lagasca y S.R. Clemente, formó parte del grupo de iniciados adoctrinados por A.J. Cavanilles aún antes de su nombramiento como director del Jardín de Madrid (cf. "papeles atribuidos a Simón de Rojas Clemente". Archivo del Museo de Ciencias Naturales, sin catalogar); a él se le encomendó herborizar la mitad meridional de la Península, en 1803, con objeto de completar la Flora Española; parte del material recolectado fué hecho público, con bastante posterioridad a su recogida, por M. Lagasca. No faltaron corresponsales del Real Jardín en Sevilla durante este período, dedicados con preferencia al envio de cereales, asi por ejemplo, M. Alarcón (Ecija) o A. Grison (Sevilla), su correspondencia con el Real Jardín se conserva entre la mantenida por M. Lagasca (Arch. R.J.B. leg. I,56 y I,57) o por S.R. Clemente (Arch. R.J.B. leg. I,57 a I,58).

48. No incluímos la interesante labor desarrollada por S.R. Clemente, desde marzo de 1804 hasta octubre de 1805, tiempo suficiente para realizar una detallada "Historia Natural del Reino de Granada", lamentablemente inédita aún en nuestros dias. Sus materiales están repartidos entre el Arch. R.J.B. y el Museo de Ciencias Naturales; si bien en el primero se conserva toda la documentación de carácter científico (leg. I,60,2; I,60,3); parte de estos datos fueron publicados por M. Colmeiro en Rev. Progr. Ci. Exact. Fis. Nat. 14:39-58. Madrid, 1863 (bajo el título, atribuido a S.R. Clemente, "Tentativa sobre la liquenología geográfica de Andalucia").

49. Sobre el A. Cabrera cf. L. Pérez Fernández, El magistral Cabrera. Cádiz, 1901; L. Pardo, "Breve noticia histórica del ficólogo español D. Antonio Cabrera". Nueva Notarisia, fascícolo conmemorativo: 109-116. Padova, 1925; J.M. León Domínguez, Recuerdos Gaditanos. Cádiz, 1897 (el capítulo titulado "El Magistral Cabrera" en pp. 28-49).

50. Sobre la tertulia reunida en torno a esta ilustrada donde participaba activamente el magistral Cabrera, cf. A. Orozco Acuaviva. La gaditana Frasquita Larrea, primera romántica española. Cádiz, 1977.

51. Un comentario sobre este grupo de ilustrados en M. Ruiz Lagos, Política y desarrollo social en la baja Andalucía. Madrid, 1976. Sobre algunas Sociedades Económicas Andaluzas se ha ocupado este autor en Ilustrados y reformadores en la baja Andalucía. Madrid, 1974.

52. Asi se desprende de los datos contenidos en los libros "Copiador de oficios y representaciones". (L-186); "Correspondencia exterior". (L-200) y "Libro del Censor" (L-198) pertenecientes a la Sociedad Económica de Amigos del País de Cádiz. Una aproximación a esta Sociedad en A. Orozco Acuaviva "La Real Sociedad Económica de Cádiz" En: La burguesía mercantil gaditana (1650-1868), pp. 2630273. Cádiz, 1976. La documentación se conserva en la Real Academia de Medicina de Cádiz, agradecemos al Prof. Orozco la facilidad dispensada para su consulta. 
IMPORTANCIA DE LA OBRA DE E. BOISSIER EN EL CONOCIMIENTO DE LA FLORA GRANADINA.

Fueron precisamente tierras granadinas las primeras que pisó Boissier en el sur de España, al inicio de su famoso "Voyage botanique dans le Midi de l'Espagne pendant l'année $1837 "$.

La ciudad de Motril le albergará tras varios días de adversidades a bordo de una pequeña e incómoda nave a vela, "... Nous eûmes le plaisir de nous trouver le matin en vue des blanches maisons de Motril, òu nous devions débarquer une partie de la cargaison".

Su gran capacidad para plasmar hasta el más mínimo detalle de todo cuanto observaba en este "hermoso y desdichado pais" (como se expresaba frecuentemente al referirse a España, azotada por la guerra Carlista), nos proporcionó un documento insustituible sobre el entorno vegetal del reino de Granada. Buena prueba de ello son sus pinceladas sobre la vega y ciudad de Motril, "...Les champs étaient couverts des plantations de coton, et surtout des cannes à sucre qui croissaient là avec une vigueur tout-à-fait tropicale". "Les maisons de la ville ont un seul étage, le toit plat, et sont enduites en dedans comme en dehors d'une couche de chaux d'une éclatante blancheur".

Cuando herborizaba en los alrededores de Motril, se sorprende de 1 a abundancia de chumberas que "prestan al lugar un aire africano", y descubre Sierra Nevada, sin duda la meta prioritaria de su largo viaje "Et plus au fond je découbris avec émotion, par-dessus les premiers plans du tableau, les sommets glacés de cette" Sierra Nevada si desirée, le picacho de Veleta à gauche, puis le Mulhacén un peu sur la droit", y más tarde, desde 10 a 1to de Sierra Tejeda comentaba "...et j'aperçus enfin distintement la ville de mes rêves (Granada) ...Derrière elle s'élevait la Sierra Nevada tachetée de neige".

Como han opinado Bocquet \& a1. (1985:12), fué probablemente Philipp Barker Webb (1793-1854), que había visitado España en 1827 , el autor que ejerció la influencia necesaria sobre el joven Boissier para despertar su interés por el reino de Granada. Otro argumento que le hizo decidirse fué la falta de estudios botánicos sobre él mismo "le royaume de Grenade n'avait été parcouru que par un petit nombre de botanistes tout à fait en passant, et qu'il est peut-être, quand à sa Flore, la portion la plus favorisée de la Péninsule, à cause de la variétée de ses expositions".

Antes que Boissier, únicamente Thalacker, Bory de st. Vincent, Simón de Rojas Clemente, Webb y Rambur habian visitado el reino de Granada, recolectando plantas y describiendo algunos táxones nuevos.

Después de herborizar en Motril, embarcó de nuevo en Salobreña, pero el mal estado de la mar le hizo detenerse de nuevo en Velilla, donde decidió hacer el resto del viaje a Málaga por tierra "Le lendemain, nouvelle relâche forcée à la tour de Velilla, à quatre lieues à peine à l'ouest de Motril; cette fois ma patience était à bout, et, laissant mon bagage sur la felouque, je me décidai à faire le reste de la route par terre... et nous quittâmes le bord en faissant le serment solennel de ne plus remettre le pieds sur un llaud valencien, et surtout de nous abstenir à jamais de riz bouil1i".

Tras pasar la noche en Almuñecar, se dirigió a. Nerja; en el 


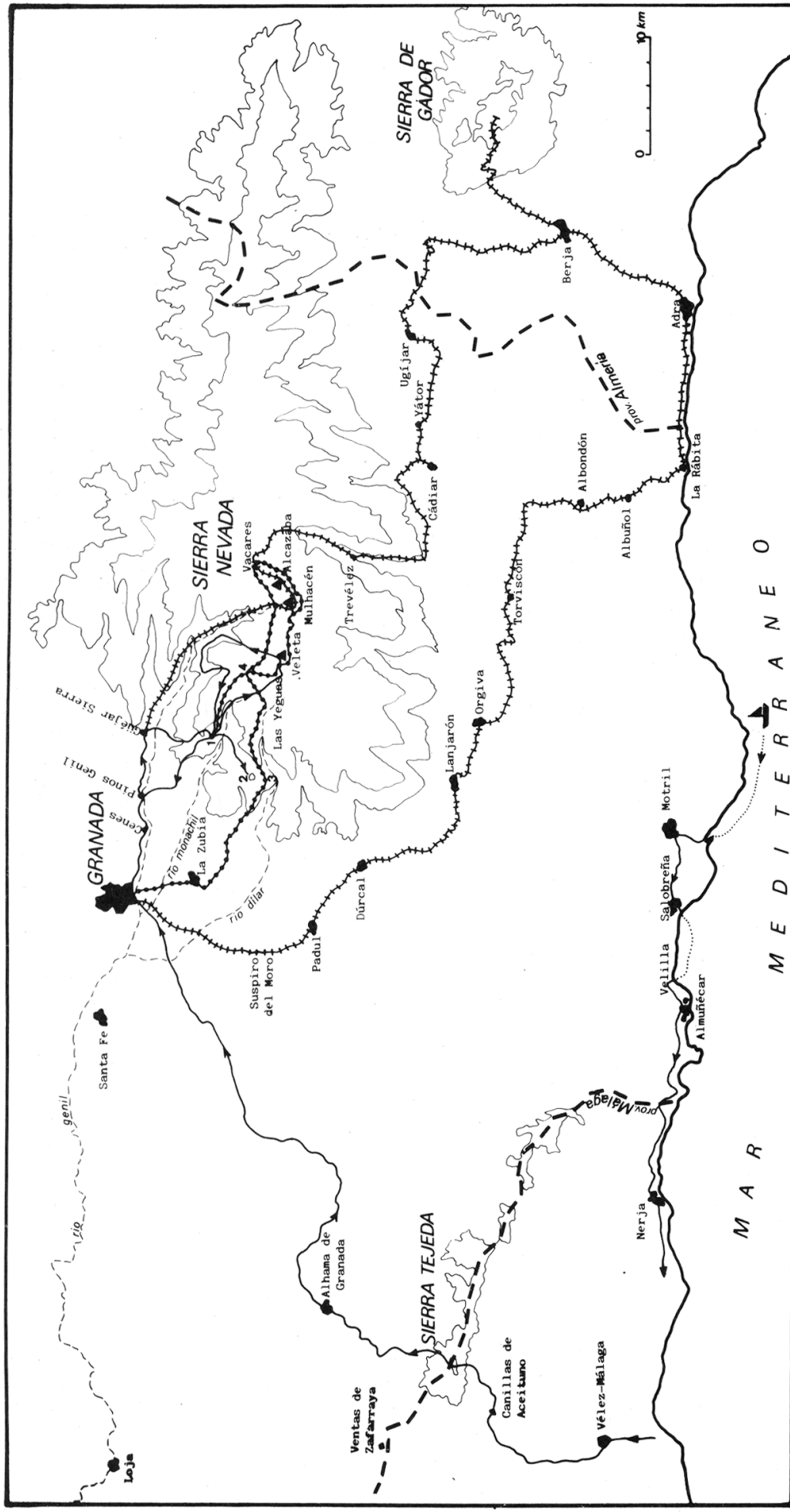


camino descubre Celastrus europaeus. Después de sus trabajos en la provincia de Málaga, que son el objeto de otro artículo, Boissier se encaminó hacia Granada, por el sendero que, a través del valle de Vélez Málaga, conducía al Boquete de Zafarraya; pero en lugar de pasar por este último, se desvió hacia Canillas de Aceituno, desde donde iniciaría el ascenso a la Sierra Tejeda, a cuyo estudio dedicó varios días "Quatre journées furent consacrées à l'exploration de ces richesses... Je faisais plusieurs excursions par jour, descendant sur 1'un ou sur 1'autre versant".

En esta singular Sierra descubrió Jasione penicillata, Arenaria erinacea, Silene tejedensis, Helianthemum viscidulum, Centurea Bonbycina, Anthyllis tejedensis, Coronilla eriocarpa. Teucrium fragile, Thymus longiflorus, etc. y otras especies que después encontraría tambien en Sierra Nevada (asi 1o indicó en 1 a reseña de las localidades clásicas), como Acer granatense, Dianthus brachyanthus, Erodium cheilanthifolium, Cynoglossum pustulatum, Andryala agardhii, Cyanara alba, Anthemis granatensis, Poa ligulata, Trisetum velutinum, etc.

Están llenas de gracejo sus reseñas acerca de la incredulidad de las gentes del lugar sobre los verdaderos fines de su trabajo, "personne ne voulait croire aux explications toutes simples que je donnais sur le but de mes recherches, mon baromètre surtout intrigait fort ces braves gens, ils secouaient la tête d'un air significatif. Coger pinchos, medir sierras y por gusto, no puede ser ..., disaient-ils"; y más tarde, en las minas de la Sierra de Gádor comentaba "d'abord personne ne voulait croire que je fusse là pour cueillir des herbes, et j'était à chaque moment pris à par divers individus qui, me croyant venu dans le but d'explorer secrètement les mines, me proposaient de me faire connâtre des riches filons et de les exploiter avec moi".

En Sierra Tejeda, como en el resto de su viaje por Granada, Boissier desarrolló al máximo sus indiscutibles aptitudes como botánico y montañero; ya no le acompañaban los Haenseler y Prolongo que tanto le ayudaron en tierras malagueñas, y turo que guiarse exclusivamente por sus conocimientos y su indudable intuición. Su fascinación por las tierras granadinas hizo que cambiara los epitetos "baetica", "haenseleri" y "prolongoi", por los "granatensis", "nevadensis", "glaciale" y "nivalis" que se referian a la provincia y sierra de sus sueños.

No obstante, su honestidad y gran sentido de la equidad, le hicieron dedicar numerosas especies a los botánicos que le habian precedido en la visita al reino de Granada, Linaria Salzmanni, Gentiana Boryi, Leontodon Boryi, Festuca Clementei, Prunus Ramburei, Teucrium Webbianum, o que habian recogido las exsiccatas sobre las que describió nuevos táxones, como Iberis Bourgaei (Baza, Bourgeau), Anthyllis Ramburei (Sierra de Alfacar, Rambur), Astragalus Clusii (c.Guadix, Clusio), Potentilla Reuteri (Dornajo, Reuter) y Saxifraga Camposii (Sierra de Loja, Campo).

E 125 de junio de 1837 , finalizadas las herborizaciones en la Sierra de Tejeda, descendió por la vertiente septentrional de la misma hasta alcanzar Alhama de Granada y, finalmente, Granada (figura 1).

Ya en Granada, deja a sus guías y atraviesa toda la ciudad a la búsqueda de $1 \mathrm{a}$ Alhambra. "Ma prmière visite fut pour l'Alhambra vers lequel je m'acheminai sans guide, jouissant singulièrement de ce petit voyage de découverts à travers des rues tortueuses de Grenade". Al1i descubrió Antirhinum 
glutinosum, "in rupestribus montium Granatensium ab urbe Granadâ ubi muros arcis Alhambra adornat usquè ad regionem alpinam".

Cuando intenta informarse en la ciudad sobre Sierra Nevada, descubre, con sorpresa, que nadie sabe indicarle el camino para subir al Veleta; en la fecha de su llegada a la ciudad, a primeros de julio, los buenos conocedores de la Sierra, pastores y nevaderos, se encontraban en ella realizando sus tareas; "et d'après quelques vagues données je me mis en route le 2 juillet au matin, le long de la vallée du Xenil".

Boissier realizó tres viajes a Sierra Nevada, en el primero, a través del valle del Genil, pasando por Cenes y Pinos Genil, llega a Güéjar Sierra, donde se aloja en la casa de un vendedor de vino; al describir el paisaje vegetal de este singular pueblo serreño, se sorprende de la coexistencia de los cultivos de vid y olivo"la vigne et l'olivier ont leur limite supérieur aux environs de Güéjar; Il est assez singulier que ces deux végétaux qui s'arrêtent à des latitudes si différentes dans l'Europe centrale, aient partout dans le royaume de Grenade les mêmes zones de végétations".

Tampoco en Güéjar Sierra consigue informarse sobre el acceso al Veleta, pero le aconsejan pasar por el cortijo de San Jerónimo, en el valle del rio Monachil. A11i decide establecer el centro de sus estudios, debido a las comodidades del lugar, para él y sus acompañantes, y la amabilidad de los habitantes del lugar. Sus escarceos por los alrededores le proporcionan numerosos descubrimientos, como Ranunculus granatensis, Paeonia coriacea, Helianthemum papillare, Imperatoria hispanica, Laserpitium longiradium, Anchusa granatensis, Linaria verticillata, Lavandula lanata, Nepeta granatensis, etc.

Desde San Jerónimo visitó el Trevenque, donde descubrió bellos endemismos, algunos de área muy reducida, como potentilla petrophila, Helianthemum pannosum, Galium erythrorrhizon, Scabiosa pulsatilloides, Santolina elegans, 1 a magnífica y rara Haenselera granatensis, etc.

Otro día se dirije al Veleta, remontando el barranco de Benalcázar, pero, ya tarde, ha de regresar cuando se encontraba en las faldas del pico, su afán de visitar las cumbres más elevadas y la imposibilidad de alcanzarlas desde San Jerónimo, le deciden a trasladarse a un lugar más elevado, el prado de las Yeguas, donde permaneció varios días en un mísero hato de pastores.

El día 12 de julio consiguió alcanzar la cúspide del Veleta, desde donde describe, emocionado, el panorama que le rodeaba, desde Sierra Nevada a las Costas de Africa, desde Cabo de Gata a las Serranías de Ronda. "Mes compagnos, moins habitués aux montagnes et ressentants à 1 a fois les effects de la fatigue et ceux de la rareté de l'air, s'étendirent à terre por dormir pendant que j'étudiais l'admirable panorame deployé devant moi".

Al día siguiente, vuelve de nuevo para estudiar detenidamente el Corral del Veleta, al que considera un glacial en miniatura. Esta vez no regresa a las Yeguas, sino que desciende por el barranco del Guarnón hasta la foresta de Quercus pyrenaica y de nuevo asciende por el barranco de San Juán hasta los peñones de San Francisco, volviendo a las Yeguas después de tres días. Regresa a San Jerónimo, visita de nuevo el Trevenque y vuelve a Granada pasando por el Purche, "Je rentrai à Grenade retrouvant avec joie les douceurs de la vie civilisée après une excursion de seize jours dans la montagne". 
Con la experiencia de esta primera excursión, e 123 de julio emprendió su excursión más ambiciosa al Mulhacén y las Alpujarras. Llega a Güéjar Sierra y continúa por el valle del Geni1, loma de Maitena, alcanzando, ya cercana la noche, el pié de las imponentes moles del Alcazaba y Mulhacén. Al día siguiente, desde la cabecera del barranco del Poqueira, 1lega a la cúspide del Mulhacén; desciende por el valle de Siete Lagunas, puerto y laguna de Vacares y pone camino a Trevélez.

Después de un día de permanencia en Trevélez a causa de la lluvia, baja hacia Gádiar y llega a Berja (Almería), desde donde explora la Sierra de Gádor.

Desde Adra viaja cerca de la costa hasta La Rábita, ascendiendo de nuevo por Albuñol, Albondón, Torviscón, Orgiva y Lanjarón. Entre estas dos últimas localidades descubre Reseda lanceolata y Lavatera oblongifolia.

Aunque pensaba subir al Caballo, la pesada carga de plantas que transportaba la caravana hizo la empresa imposible, por lo que decidió volver a Granada a través del puerto del Suspiro del Moro, "Je m'arretâi là quelques instants pour saluer la riante Vega éclairée par le soleil couchant, c'était à cette plase même, 345 ans auparavant, Abi Abdilehi ou Boabdil, dernier roi more, jeta un dernier regard sur cette Grenade laquelle il disait un éternel adieu".

El balance de estas dos excursiones no pudo ser más positivo. Las innumerables bellezas florísticas de sierra Nevada quedarían descubiertas para la Ciencia y, las localidades de San Jerónimo, Cortijo de las Viboras, Veleta, Mulhacén, valles de los ríos Monachil y Dílar, Dornajo, Barranco de Benalcázar, Vacares, Prado de las Yeguas, Borreguiles, etc. Pasarían a ser clásicas en el estudio de la flora nevadense.

Más de medio centenar de especies y numerosísimas variedades fueron descritas por el propio Boissier, como Ranunculus acetosellifolius, Cotoneaster granatensis, Prunus ramburei, Potentilla nevadensis, Saxifraga nevadensis, Erodium daucoides, Silene boryi, Genista versicolor, Eryngium glaciale, Ferulago granatensis, Meum nevadense, Linaria glacialis, Sideritis glacialis, Lonicera arborea, L. esplendida, Centranthus nevadensis, Plantago nivalis, Artemisia granatensiş, Centaurea granatensis, C. monticola, Crepis oporinoides, Erigeron frigidum, Oporinia microcephala, Agrostis nevadensis, Festuca clementei, F. indigesta, F. pseudoeskia, F. rivularis, F. elegans, Holcus caespitosus, Trisetum glaciale, etc., o junto con el conservador de su herbario y buen amigo Reuter (1805-1872), que también visitó el reino de Granada posteriormente, en el "Pugillus" (1852), entre las que pueden señalarse Berberis hispanica, Iberis granatensis, Rumex induratus, Sagina nevadensis, Euphorbia nevadensis, Anthyl1is hispida, Lotus glareosus, Antirhinum rupestre, Linaria macropoda, Galium rosellum, Aster discoideus, Picris longifolia, Carex camposii, C. nevadensis, Agrostis scabriglumis, etc.

E1 tercer y último viaje a Sierra Nevada tuvo por objeto únicamente la recolección de semillas y plantas de floración tardia, por lo que Boissier no dió muchos detalles sobre el mismo. Sube de nuevo a San Jerónimo recorre la cuenca del río Monachil y en la Cueva del Panderón establece su centro de excursiones; en dicha cueva se refugiaban dos nevaderos, que generosamente ceden su aposento al botánico forastero (durmiendo ellos a la intemperie), y al que traen provisiones 
desde Granada; alli pudo soportar las tormentas estivales, "j'en ai compté jusqu'à six dans la même journée".

Sólo relató la excursión más larga hasta el Mulhacén y Vacares. En el barranco del Poqueira,al pie del Mulhacén, descubre el Senecio elodes. El día 2 de septiembre finaliza las herborizaciones y desciende por el valle de Dílar pasando la noche en el cortijo de Rosales y alcanzando la vega de Granada a la altura de La Zubia.

Aunque pensó visitar Loja en su vuelta a Málaga, desiste de su idea para recoger semillas en Sierra Tejeda, a la que sube desde Alhama de Granada, descendiendo después a Canillas de Aceituno (Málaga).

Atrás quedaban innumerables vivencias, el descubrimiento de más de 200 táxones nuevos para la Ciencia, el reconocimiento de 1 a bondad, amabilidad y alegría de los habitantes de Granada con los que fácilmente hizo amistad y, en muchos casos, 1a añoranza por los lugares que ya nunca volvería a visitar, "Je n'oublierai jamais cet hereux petit coin de terre (Trevélez) dont les habitants ont conservé leurs vertus primitives, et qui depuis l'époque des combats entre les chrétiens et les morisques, a échappé à toutes less agitations de la malheureuse Espagne".

La montaña le magnetizaba hasta el punto de rechazar la ciudad, "le séjour de Grenade n'est pas agréable au mois d'août". En el tercer viaje a Sierra Nevada, su alojamiento lo constituiría un extraplomo cerrado por una tapia, la cueva del Panderón, muy cercana a las grandes altitudes nevadenses que visitaba repetidamente y en pleno contacto con la Naturaleza.

La Andalucía que visitó Boissier fué la menos culta, la rural, la. del puchero y el gazpacho, y también, la de las chinches y la miseria, "je passai dans toute cette contrée, et en particulier dans la partie occidentale .du royaume de Grenade, 1'été et une partie de 1'automne de $1837 \ldots$ ayant passé la plus grande partie de mon temps loin des centres de population, dans les montagnes, parmi les paysans et les bergers".

En Granada, el deseo que había expresado en las primeras páginas del "Voyage", se había conseguido plenamente, "si ce travail peut servir de base première à l'exploration du midi de 1'Espagne en particulier et être ainsi de quelque utilité pour la création d'une flore espagnole, je me croirai assez récompensé".

\section{BIBLIOGRAFIA}

BOCQUET, G., BRIQUET, J.I., BURDET, H.M., CHODAT, H., DE CANDOLLE, A.L.P.P., HOCHREUTINER, B.P.G. \& MERMOUD, M. -1985- Edmond Boissier. Botaniste génevois. 1810-1885. Conservatoire et Jardin Botaniques de Genève.

BOISSIER, E. -1839/45- Voyage botanique dans le midi de l'Espagne pendant l'année 1837. Paris.

BOISSIER, E. \& REUTER, G.F. -1852- Pugillus plantarum novarum Africae borealis Hispaniaeque australis. Genevae.

BURDET, H.M., CHARPIN, A. \& JACQUEMOUD, F. -1982- Index Boissierianus Hispanicus. Candollea 37:397-427.

BURDET, H.M., CHARPIN, A. \& JACQUEMOUD, F. -1981/84- Types nomenclaturaux des taxa ibériques décrits par Boissier ou Reuter. I. Gymnospermes à Graminées. II. Iridacées à Potamogetonacées. III. Aceracées à 
Chénopodiacées. IV. Cistacées à Composées. V. Convolvulacées à Ericacées. VI. Euphorbiacées à Guttifères. Candollea 36:543-584; $36: 381-395 ; 38: 401-441$, 751-802; 39:349-373, 771-789.

\section{IMPORTANCIA DE LA OBRA DE E. BOISSIER EN EL CONOCIMIENTO DE LA FLORA MALAGUEÑA}

La presencia de Pteris lanceolata, cultivos de caña de azucar, viñedos y una buena posada donde descansar, son las primeras referencias que, sobre la provincia de Málaga, aparecen en la obra de E. Boissier, a la cual había llegado en los primeros días de mayo de 1837 procedente de Motril (Granada) y con dirección a la capital por el no siempre seguro camino de la costa.

Boissier no llegó a unas tierras botánicamente desconocidas; aunque pocos, algunos botánicos habian adelantado con sus publicaciones, colecciones y relatos las singularidades floristicas y paisajisticas malagueñas. Con seguridad fueron estos datos los que motivaron al botánico ginebrino a emprender su periplo por tierras del mediodía español. De igual manera, el acierto en la elección de los lugares visitados y el hallazgo de muchas de las especies descritas, se vieron favorecidas por la colaboración que botánicos afincados en Málaga como Prolongo y Haenseler le prestaron desinteresadamente durante su estancia en la provincia, colaboración que se prolongó con posterioridad al viaje y permitieron la redacción definitiva de 10 que podemos considerar como 1 a primera aproximación a la flora malacitana.

Málaga es una región muy heterogénea florísticamente, heterogeneidad condicionada por una acusada variabilidad en factores que como los climáticos, geológicos y orográficos, inciden positivamente sobre 1 a mencionada diversidad floristica. Un mosaico geológico formado por calizas, serpentinas, dolomias, areniscas, esquistos etc.; una posición geográfica vasculando entre 10 mediterráneo y 10 atlántico, 10 europeo y 10 africano; una quebrada orografía y un clima que oscila entre lo térmico y lo frío, lo húmedo y lo semiárido, condicionan una flora lo suficientemente atractiva por su belleza y originalidad como para impresionar muy gratamente al botánico ginebrino.

Frente a esta diversidad no tuvo que ser fácil para Boissier elegir la ruta que le permitiera obtener el cúmulo de datos que sobre la flora malagueña plasmó posteriormente en su obra. Sin lugar a duda la orientación en la ruta, fundamental para el éxito de su exploración, tuvo que venir de sus amigos y colaboradores Haenseler y Prolongo. De cualquier manera el camino elegido fué un acierto, como lo demuestra la cantidad y calidad de las especies descritas y citadas. Hoy dia, después de 150 años, el itinerario de Boissier sigue siendo el idóneo para conocér la diversidad del paisaje y vegetación malagueño.

Indudablemente Boissier no recorrió toda la provincia, pero 


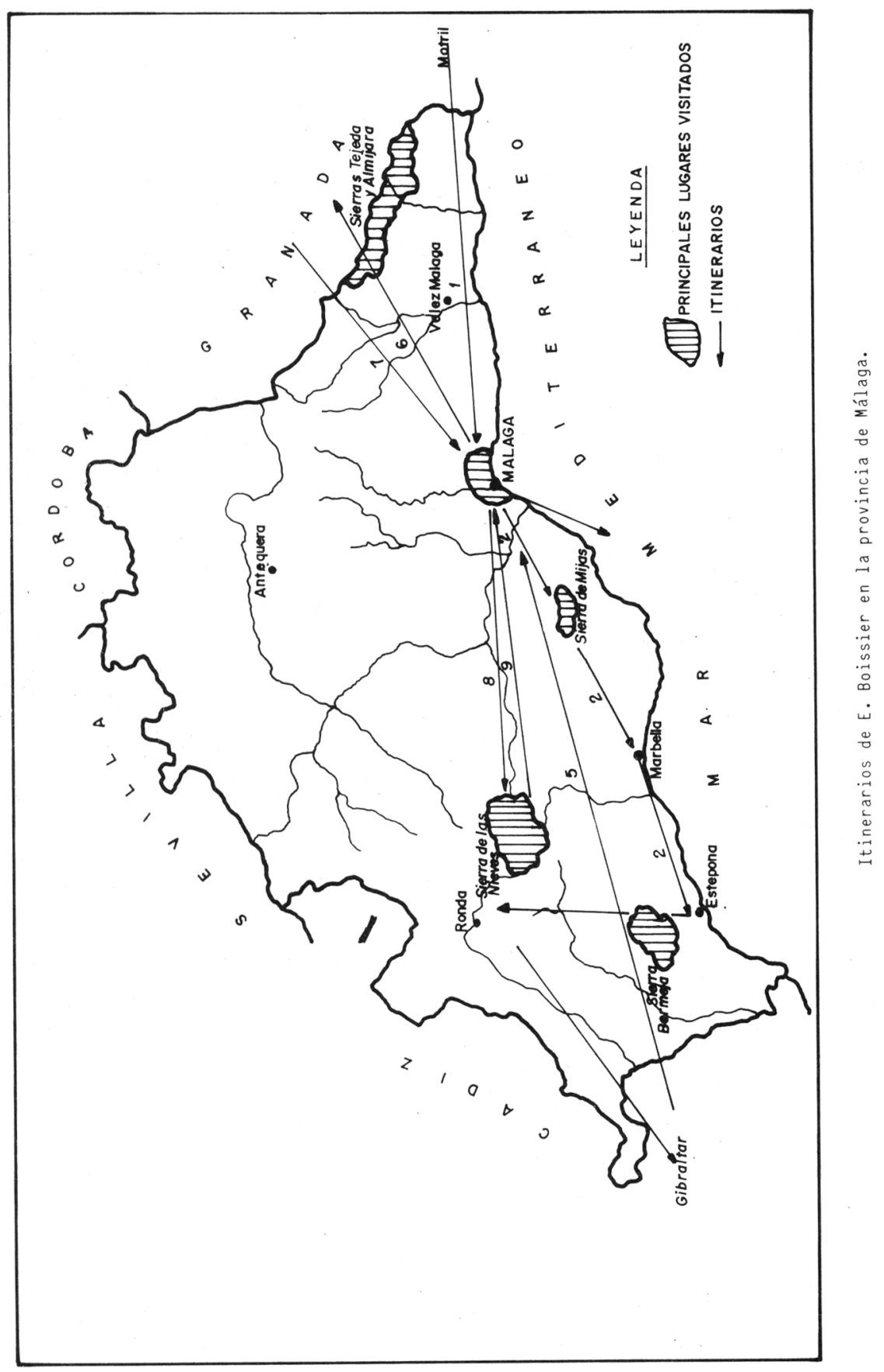


la visita a las sierras de Mijas (Mijas y Alhaurín el Grande), Bermeja (Estepona), Tejeda (Canillas de Albaida, Canillas de Aceituno, Cómpeta, etc.) y de las Nieves (Ronda, Yunquera, Tolox, etc.) le permitieron recolectar una.gran parte de las más de 2 millares de especies que, independientemente de su valor taxonómico y nomenclatural actual, fueron plasmadas en el "Voyage botanique dans le Midi de l'Espagne", lo que convierte esta obra en casi una flora de la provincia de Málaga.

Una vez llegado a la provincia de Granada, e independientemente de algunas pequeñas recoleciones realizadas durante su aproximación a Málaga y posteriormente en los alrededores de la capital, fué la Sierra de Mijas el primer lugar que Boissier recolectó de una manera sistemática. Esta sierra, a la que el botánico llegó en un inmejorable momento, le ofrece la oportunidad de estudiar una flora caracterizada por la termicidad climática, sustrato fundamentalmente dolomítico y una orografía muy quebrada. Entre las numerosas especies que Boissier cita de esta sierra podemos destacar las siguientes (1): Fumaria corymbosa, Sisymbrium laxiflorum, Reseda undata, Sarothamnus malacitanus,, Ononis speciosa, Herniaria scabrida, Saxifraga globulifera, Echium albicans, Macrochloa arenaria, Anthyllis podocephala, etc.

Un trozo de rama de un abeto desconocido, visto en el herbario de Haenseler, le incita a visitar Sierra Bermeja de Estepona, lugar a donde habia llegado desde Marbella. Esta sierra no sólo proporciona a Boissier el placer de ver "in situ" y describir nuestro Abies pinsapo, sino que además le of rece la posibilidad de estudiar lo que para él es una vegetación muy singular en función de la existencia de un sustrato fundamentalmente serpentínico. Pinsapares, alcornocales, brezales y jarales se alternan ante el botánico sorprendido y maravillado por las singularidades floristicas que esta sierra le ofrece. Entre otras se citan de Sierra Bermeja las siguientes especies: Brassica longirostra, Arenaria capillipes, Arenaria retusa, Ulex boeticus, Genista haenselerí, Saxifraga gemmulosa, Asperula paniculata, Staehelina boetica, Serratula boetica, Digitalis laciniata, Teucrium haenseleri, Abies pinsapo, Alyssum serpyllifolium, Linaria saturejoides, etc.

La curiosidad por conocer feria tan singular como la de Ronda, incita al viajero a modificar su previsto viaje a Gibraltar y marcha desde Estepona hacia la Sierra de las Nieves. Lo temprano de la estación (mayo), una indisposición del botánico, y la falta de papel para herborizar, hace que esta primera visita sea poco fructifera. Posteriormente, después de visitar Sierra Nevada y a sabiendas de lo adelantado de la estación (septiembre), Boissier vuelve a la Sierra de las Nieves acompañado de Prolongo y Haenseler, fundamentalmente, para recolectar piñas de pinsapo y confirmar su inclusión en el género Abies. Realmente no tuvo la oportunidad de visitar estas hermosas sierras calizas en su mejor momento, pero son numerosas las especies que cita entre las que podemos destacar las siguientes: Sarcocapno boetica, Draba hispanica, Ulex boivini, Anthyllis podocephala, Saxifraga arundana, Galium pulvinatum, Senecio lopezii, Centaurea clementei, Linaria clementei, Linaria platycalyx, Lavandula lanata, Salvia candelabrum, Thymus granatensis, Quercus alpestris, etc.

Por último, y camino de Granada, Boissier llega a Sierra Tejeda. La fecha (junio) no puede ser más oportuna, a diferencia de la Sierra de las Nieves, Sierra Tejeda se 
encuentra en su mejor momento. El mismo se considera el cuarto y más afortunado de los botánicos que han tenido hasta ese momento la oportunidad de visitarla. En la zona más alta descubre una vegetación de tipo alpino, formada como él mismo dice, por un considerable número de especies soberbias. A cada paso descubre nuevas plantas que causan su admiración y le fuerzan a permanecer más de 10 previsto a fin de recolectar perfectamente esta muestra de la alta montaña mediterránea. Entre las numerosas especies que cita podemos destacar: Peonia coriacea, Vella spinosa, Ptilotrichum spinosum, Helianthemum viscidum, Silene tejedensis, Arenaria armeriastrum, Arenaria erinacea, Adenocarpus decorticans, Anthyl1is tejedensis, Astragalus creticus, Coronilla eriocarpa, Geum sylvatica, Centaurea bombycina, Centaurea boissieri, Centaurea prolongi, Andryala agardhii, Jasione penicillata, Linaria raveyi, Teucrium fragile, Thymus longiflorus, Armeria filicaulis, etc. "Si este trabajo puede servir de base primera a la exploración del mediodia de España en particular, y ser asi de alguna utilidad para la creación de una flora española, me creeré suficientemente recompensado", este pensamiento de Boissier expresado en abril de 1845 en el prefacio de su obra (Boissier 1839-45), y desde nuestra perspectiva del año 1987, nos permite exponer sin ninguna clase de dudas que Boissier ha sido largamente recompensado, su obra será siempre recordada y utilizada en todos los estudios futuros sobre la flora malagueña y española, sus epitetos malacitanus, tejedensis, arundana, boetica, prolongoi y haenseleri serán una permanente muestra de su agradecimiento hacia la tierra que tantas alegrias le proporcionó y a los botánicos que tanto le ayudaron.

(1) La nomenclatura coincide con la utilizada por Boissier en su obra.

BIBLIOGRAFIA

BOISSIER, E. -1839/45- Voyage botanique dans le Midi de l'Espagne pendant l'année 1837. Paris. 